\title{
Uma leitura fenomenológica sobre a intersubjetividade no digital/on-line
}

\author{
A phenomenological reading on \\ intersubjectivity in digital/on-line world
}

\author{
Nara Helena Lopes Pereira da Silva*1 \\ Carlos Aurélio Ventura Morujão*2
}

Este trabalho busca refletir sobre as vivências on-line e a relação com o mundo da vida, a subjetividade e a intersubjetividade. Foram utilizadas as obras de Husserl (1950a, 1950b, 1952, 1954), visando o retorno à intuição experiente e metodologicamente orientada pelas reduções fenomenológicas. Compreender os aspectos estruturantes através das reduções permite destacar as implicações da vida híbrida, como fragmentação das perspectivas, a dinamicidade e a velocidade de transmissão da informação por imagens bidimensionais em formato de janelas, sem materialidade e espacialidade concreta, que promovem uma reconfiguração perceptiva da consciência. No mundo da vida, há um esmaecimento da hierarquia entre cientifico e cultural, que modifica a esfera de valores, rompe com lógicas habituais de sucessão temporal e contiguidade e torna a experiência do tempo histórico fugaz. Reflete-se sobre a inserção das tecnologias nos cuidados à saúde mental. Sugere-se o incentivo à literacia digital e a legitimação das experiências sensíveis no mundo.

Palavras-chave: Fenomenologia, psicologia fenomenológica, internet

*1 Universidade de São Paulo - USP (São Paulo, SP, Brasil).

*2 Universidade Católica Portuguesa (Lisboa, Portugal). 
Este trabalho busca dar visibilidade às influências do avanço tecnológico na subjetividade a partir da fenomenologia husserliana. Para além da naturalização do uso das tecnologias digitais na vida ou em tratamentos voltados ao sofrimento psíquico, é necessário dar um passo anterior e refletir sobre este cenário de mistura entre vivências humanas e digitais: como o fenômeno on-line ocorre no mundo da vida e como ele afeta a compreensão que o sujeito tem de si mesmo e da sua relação com o outro?

O desenvolvimento da internet permite a entrada do homem em um novo universo de criação e recria o próprio homem. As tecnologias digitais surgem como um marco para a busca e compartilhamento de conhecimento e influenciam de modo significativo os hábitos perceptivos, a partir de novas formas de imersão na realidade e de interação com os outros, de tal modo que se torna tênue a distinção entre vivências on-line e off-line. Tais tecnologias estão cada vez mais sendo reconfiguradas como extensão do próprio corpo e da vida. Abrangem não somente dispositivos para uso pessoal, mas também sistemas de biotecnologia, influenciando profundamente o ser humano nas dimensões psíquicas, físicas e culturais. Além disso, os dispositivos digitais convivem simultaneamente com o homem, de modo que os elementos naturais - corpo - misturam-se com os artificiais objetos tecnológicos (Solari, 2005).

O relacionamento entre homem e tecnologias configura um convívio próximo de mútuo benefício. $\mathrm{O}$ fenômeno interessante não é apenas a existência ou a renovação constante das tecnologias, mas a relação que o homem tem com elas, provocando emoções e sentimentos sem uma efetiva distinção. Contribuem com a evolução humana, quase que coincidindo com a evolução biológica. Ambas as evoluções, a tecnológica e a biológica, estariam, segundo Zilli (2008), intimamente ligadas, criando uma evolução biotecnológica, na qual ao centro está a unidade biológica "homem", identificado como um híbrido da biotecnologia em contínua transformação. 
A relação do homem com as tecnologias acontece no solo do mundo da vida. Segundo Husserl (1954) o mundo da vida "se configura através de uma relação direta com este último [mundo] e com as outras subjetividades que dele fazem parte" (pp. 126-141; tradução nossa). Em sua filosofia tardia, esse mundo adquire duas dimensões (Álvarez, 2003): primeiro, sua dimensão de mundo histórico, o mundo da vida cotidiana e da cultura, subjetivo, constituído por sedimentações do passado, que varia a cada época e nas diferentes culturas; e, segundo, sua dimensão de mundo natural-perceptivo ausente de predicativos culturais, um extrato puramente sensível, comum a todos e a-histórico. É possível, contudo, atenuar aparente oposição entre as duas mencionadas dimensões, quando se reflete que, no mundo da vida, todas as "relatividades" que lhe são próprias repousam sobre uma estrutura geral, "um a priori distinto da legalidade fática das ciências físico-matemáticas e que não é outra coisa que o mundo natural-perceptivo" (Álvarez, 2003, p. 240; tradução nossa). Superada essa oposição, as tecnologias digitais interferem, mesmo que de forma diferenciada, em cada uma dessas dimensões: por um lado, constituem um produto altamente sofisticado da cultura dos séculos XX e XXI; por outro, condicionam a percepção do mundo, abrindo a possibilidade 616 de novas perspectivas sobre ele.

Entre os anos de 1912 e 1928 — entre a redação da versão inicial de Ideias II e as últimas revisões do manuscrito, que renunciará a publicar - Husserl desenvolve suas primeiras noções sobre o mundo da vida (Lebenswelt). Nesses esboços, o mundo da vida é concebido enquanto "mundo circundante do $\mathrm{Eu}$, que obtém por essência a sua individuação através da relação com o Eu que o experencia e que troca suas experiências com outros indivíduos" (Husserl, 1952 , p. 301; tradução nossa). Nesse sentido, tudo que está no mundo da vida é objetivo e é, também, uma doação subjetiva à posse do Eu, do outro e à posse comum de todos. Se, para o Eu, os fenômenos possuem o seu aqui e agora como correlatos de uma intuição, Husserl (1952) afirmará que:

uma intersubjetividade por si mesma constitui o mundo circundante e, se se deixar determinar pelo que tem diante de si no mundo circundante, por outro lado, o determina ativamente e, eventualmente, o configura; este [mundo circundante] tem, todavia, a individuação secundária do que "está diante", enquanto a individuação originária, absoluta, reside no próprio Eu. (p. 301; tradução nossa)

Essa passagem do parágrafo final do texto de Ideias II, é central para a compreensão do on-line. Nela sobressaem duas características da abordagem fenomenológica do mundo da vida e da intersubjetividade. Husserl põe em 


\section{ARTIGOS}

relevo, ao mesmo tempo, a prioridade do Eu para a fenomenologia (a reflexão começa por uma livre decisão e o sentido do que acontece no mundo passa por mim e deve ser validado por mim) e o carácter de comunidade intersubjetiva que é própria dos Eus, empenhados na constituição de um mundo comum.

O tema do mundo da vida, embora se configure em suas nuances no desenvolvimento filosófico de Husserl, torna-se central na fenomenologia em 1936, na obra A crise das ciências europeias. Nessa obra, Husserl mostra e testa o sentido interior dos considerados fatos históricos, por meio de uma análise intencional dos problemas da cultura e da história, considerando, também, o lugar da ciência. A vida intencional da consciência se desvela em suas múltiplas facetas, sendo a atividade científica um tipo de atividade intencional, motivada pelos interesses do conhecimento. Cada intencionalidade constitui objetos que são correlatos a essas atividades. O ser humano se volta intencionalmente aos fenômenos e atribui sentidos, através de vários níveis de relação intencional, que devem ser cuidadosamente diferenciados, bem como o modo de aparecimento dos respectivos correlatos. A fenomenologia busca, por meio de uma análise intencional dos atos, explicitar as várias modalidades da razão se relacionar com os entes e de estes se manifestarem a ela. Se, em um primeiro momento, o método fenomenológico parece consistir num distanciamento face à realidade, segundo uma expressão consagrada, ele "põe entre parênteses" a realidade. Isso acontece para que, no final, os fios intencionais possam ser restabelecidos, uma vez que essa realidade é compreendida em seu sentido. Esse procedimento recebeu, em Husserl, o nome de redução fenomenológica. $\mathrm{O}$ interesse filosófico volta-se exatamente para a subjetividade, pois é nela que se dá o mundo e as objetividades que dele fazem parte, com o seu sentido de ser. Aprofundando o trabalho da redução e dirigindo-se ao mundo da vida, o filósofo coloca em questão, também, a compreensão científica objetiva que desconsidera a subjetividade como fonte de conhecimento do mundo:

Pode o mundo, e a existência humana nele, ter na verdade um sentido, se as ciências só admitirem como verdadeiro aquilo que é deste modo objetivamente verificável, se a história não tiver mais nada a ensinar senão que todas as figuras do mundo espiritual, todos os vínculos de vida que a cada passo mantém o homem, os ideais, as normas, se forma e voltam a se dissolver em ondas fugazes, que sempre assim foi e será, que a razão sempre terá de se tornar sem sentido, a benfeitoria, uma praga? Será que podemos nos satisfazer com isso, será que podemos viver neste mundo, cujo acontecer histórico não é outra coisa senão um encadeamento interminável de ímpetos ilusórios e amargas decepções? (Husserl, 2012, p. 4) 
Husserl, na primeira parte do livro A crise das ciências europeias e a fenomenologia transcendental, introduz o tema da crise das ciências como expressão da crise radical da vida da humanidade, no sentido de crise não na base das ciências, mas na redução da ideia da ciência em mera ciência de fatos, abstraindo-se da relação com a vida subjetiva. Segundo Husserl (2012), "o homem é um ser que se decide livremente na sua relação com o mundo" (p. 3), livre nas possibilidades de configuração racional de si mesmo e de seu mundo circundante. A temática do mundo da vida e da crise das ciências possibilita refletir sobre problemáticas da idade moderna e que se atualizam em questões atuais. Embora suas colocações estejam datadas no início do século XX e sejam direcionadas a uma crítica ao conhecimento da época, os percursos trilhados pela ciência, sua constante atualização e evolução, tem dado expressividade ao desenvolvimento tecnológico, promovendo outras perspectivas de objetificação da vida.

\section{Subjetividade e intersubjetividade}

O método fenomenológico propõe mudar a atitude de olhar o mundo, conhecendo-o conforme este se mostra à consciência, neutralizar o complexo de atitudes dominantes em que o aparecimento do mundo é condicionado por preconceitos não tematizados, voltando-se para o modo como as coisas se dão em si mesmas. O que distingue o método fenomenológico do método de outras correntes filosóficas dos séculos XX e XXI é que para a fenomenologia o dar-se em si mesmo das coisas não pode ser analisado independentemente da consciência à qual elas se dão; por conseguinte, mesmo uma atitude científica que ambiciona obter um conhecimento em "terceira pessoa", que queira descrever os modos de doação sem ser afetado pela perspectiva de quem a vê, distancia-se do fato de que as coisas estão diante da consciência e essa consciência está diante das coisas. As objetividades se doam à consciência e a validade do conhecimento almejado resulta do fato de que este conhecer acontece da mesma forma a ele e a outros sujeitos, outros cientistas empenhados na realização dos mesmos interesses cognitivos. A fenomenologia se ocupa, portanto, da aplicação do método de análise das atividades intencionais que estão na base do conhecimento, busca estudar as experiências humanas e os modos como as coisas se apresentam elas mesmas por meio dessa experiência (Sokolowski, 2012). Dessa forma, o estudo voltado para a apreensão 


\section{ARTIGOS}

sobre como se desvela o estar com o outro mediado pela internet, reenvia para o estudo do humano que vivencia o on-line e, também, para o modo como os fenômenos se manifestam em ambiente digital e como a própria experiência on-line está implicada na vida humana.

Ao sair da atitude natural, a fenomenologia apresenta um convite para a compreensão reflexiva, ao se direcionar às estruturas constitutivas do mundo, desenhando gradativamente um percurso metodológico, na tentativa de elucidar como é possível a apreensão dos fenômenos através da intencionalidade da consciência, assumindo com rigor o posicionamento em que o ego se coloca em atitude reflexiva no campo transcendental, em busca de uma contínua clarificação das evidências (Sanchez, 2014). Consciência, no campo da fenomenologia, é entendida como um complexo de atos e operações próprios do sujeito que reflete e que, também, estão presentes nos outros sujeitos. "Cada captação individual no âmbito da atitude natural pode ser transformada em ideia graças à captação das suas estruturas invariantes, dadas por determinada visão que ocorre na dimensão da consciência, e assim compreendida em regime de universalidade eidética" (Husserl, 1950b, p. 330). É em Meditações cartesianas (Husserl, 1950a) que Husserl ultrapassa a perspectiva solipsista do ego e instaura na intersubjetividade o fundamento superior da objetividade:

$\mathrm{Na}$ minha própria experiência, experiencio não apenas a mim mesmo, mas também ao outro, na forma particular da experiência do alheio. [...] o ego transcendental, concretamente apreendido capta tanto a si próprio no seu ser próprio primordial como aos outros ego transcendentais, sob a forma da sua experiência transcendental do alheio, se bem que não sejam já dados na originalidade e na evidência apodítica pura e simples, mas antes, numa evidência de experiência externa. Experiencio, conheço em mim o outro, ele constitui-se em mim - espelhado apresentativamente não como original. (p. 187)

Seguindo o percurso proposto nas Meditações cartesianas (Husserl, 1950a), especificamente na V Meditação, para compreender a experiência intersubjetiva é necessário, primeiramente, fazer uma abstração de tudo que pertence à esfera do outro, de modo a encontrar aquilo que permanece na esfera de pertença do Eu. Após efetuada a operação da redução, de conduzir ao seu extremo limite, "sobra" aquilo que pertence à esfera própria:

Por meio dessa peculiar separação abstrativa de sentido do alheio, retivemos ainda um tipo de "mundo", uma Natureza reduzida à propriedade, um eu psicofísico, soma, uma alma e um eu pessoa, inserido nessa Natureza por meio 
do soma corpóreo — as únicas singularidades distinguíveis neste "mundo" reduzido. (p. 129; tradução nossa)

Pertence ao Eu reduzido, purificado de cada sentido da subjetividade do outro, o corpo-próprio em sua peculiaridade única de não ser simplesmente um corpo físico (Körper) mas também um corpo orgânico, corpo-soma (Leib), ao qual se pode atribuir o campo da experiência sensível, ainda que de modos diversos, sendo o único corpo diretamente passível de domínio pelo Eu. O $\mathrm{Eu}$ é um sujeito psico-físico, indissoluvelmente ligado a um corpo, o qual lhe concede um conjunto de faculdades que Husserl designa, por vezes, pela expressão "eu posso" e, outras vezes, pela expressão "eu quero". Os poderes do Eu não se identificam com os poderes do corpo, mas sem este o Eu não teria quaisquer poderes e a sua única relação com a realidade seria a de um espectador desinteressado situado em lugar nenhum, um Eu fantasmático que não teria mundo e, também, não necessitaria de outros Eus para agir, para conhecer e para se conhecer.

Husserl, em Ideias II, discorre sobre a constituição do humano e afirma que "o limite entre $L e i b$ e o mundo se dá segundo a consciência dos limites do corpo, que correspondem aos limites do tato" (Husserl, 1952, p. 155; tradução nossa). Dentre as percepções, o tato é fundamental do ponto de vista ontológico. É ele que garante a existência das coisas, cuja realidade se comprova, em primeiro lugar, pelo fato de que são passíveis de toque e oferecem resistência, o que não aconteceria se a experiência delas fosse apenas de ordem visual.

É por meio dessa corporeidade vivente que se torna, também, possível compreender as relações intersubjetivas, sendo o Leib um imprescindível meio de relação: é graças a um corpo animado e expressivo que sei que estou diante de outra pessoa, ou seja, de uma subjetividade que, como a minha, pode constituir um mundo e que me constitui tal como eu a constituo. Esse corpo revela a peculiaridade de cada ser humano, a unicidade, a dignidade, a inviolabilidade e a liberdade. O encontro com o outro revela, portanto, o Leib como o único dado objetivável da alteridade pessoal (Manganaro, 2007).

Pode-se apreender dois caminhos para a descrição da experiência do outro, sendo o primeiro, referente à experiência direta com o outro, através da corporeidade do eu-próprio e do outro. Um segundo percurso caminha na direção de apreender a relação que o eu-próprio e o eu-alheio têm com o mundo (Sokolowski, 2012).

A vivência do outro é não originária; o outro é sempre outro e a transgressão da esfera do próprio jamais significará a possibilidade de uma fusão com ele. Trata-se de um ponto importante ao refletir sobre as relações no 


\section{ARTIGOS}

campo digital, pois mesmo que se defenda que as vivências on-line colocam o outro à distância, tal distância se acrescenta a uma outra, que é constitutiva da própria natureza da relação intersubjetiva, de uma relação entre duas ou mais consciências que não se fundem, mesmo estando empenhadas na constituição de um mundo comum. Essa consciência é vinculada ao corpo, não acidental, mas sim essencialmente. Uma consciência sem corpo seria uma consciência sem mundo, sem resistir e sem se afetar pelo outro, e incapaz de uma verdadeira relação com algo que não fosse ela. Husserl caracteriza a consciência como transcendental, na medida em que a sua atividade constitutiva não é redutível a nenhum tipo de causalidade mundana, seja de natureza física, seja de natureza biológica, seja de natureza social, ou outra. Ela é passível de perceber o sentido das coisas, de perceber a si mesma e de perceber-se enquanto envolvida por outras consciências.

\section{Objetivo e método deste trabalho}

Este trabalho parte do fenômeno on-line que se desvela no mundo da vida. O objetivo é promover uma reflexão fenomenológica sobre a experiência subjetiva e intersubjetiva na interface digital, partindo-se do pressuposto de que a investigação da experiência subjetiva não pode ser levada a cabo com a metodologia das ciências da natureza ou da psicologia naturalista que toma estas últimas por modelo. A "naturalização" da psique - como Husserl (1987) denunciará já em 1910 no seu ensaio “A Filosofia como ciência de rigor" —, se bem que admissível em certas circunstâncias, conduz a equívocos não só de ordem metodológica, mas sobretudo de ordem ontológica. A psique fica reduzida a uma coisa entre coisas (interagindo com elas na base do princípio da causalidade), não se atentando para a sua característica principal, a saber, o fato de ser um centro de ações reais ou potenciais que possibilitam que as coisas apareçam.

Foram selecionados como texto de referência as obras de Husserl (1950a, 1950b, 1952, 1954) já mencionadas, que serviram como fundamentação para a compreensão do mundo da vida, da subjetividade e da intersubjetividade. Propõe-se uma leitura do fenômeno on-line a partir de tais fundamentos, visando seu desvelamento na experiência fenomenológica, definida como:

aquela reflexão em que o psíquico se torna acessível a nós em sua própria essência [...] $a$ vida psíquica específica do $e u$, fluída, a vida da consciência, 
que vem observada não apenas de passagem, mas se expressa ao se contemplar as partes constituintes próprias da sua essencialidade [...] e em toda a multiplicidade dos seus horizontes. (Husserl, 1928/1988, p. 107)

\section{O fenômeno on-line e o mundo da vida}

Para uma compreensão do que acontece no encontro on-line, para apreender a modalidade de relação intersubjetiva que lhe é própria, a reflexão fenomenológica necessita percorrer etapas, a fim de gradativamente desvelar seus aspectos constitutivos. É a partir desta atitude que se coloca a questão sobre como o on-line se relaciona com o mundo da vida, como a intersubjetividade é vivenciada e apreendida enquanto experiência imediata, voltando-se, especificamente, para o fenômeno da web, em que as subjetividades entram em interação de modo síncrono ou assíncrono. O que há em comum entre uma abordagem da relação subjetiva que se processa no meio digital e a que ocorre face a face, é que a relação intersubjetiva é vivenciada por dentro antes de poder ser descrita por fora; é vivida em primeira pessoa por cada um dos intervenientes, uma atitude em primeira pessoa de uma subjetividade que se volta a ela, e que não pode ser um fato meramente objetivo.

Anterior à "redução fenomenológica", o computador é apenas um objeto tecnológico sofisticado, utilizado para certa finalidade. Após a redução, nada disto desaparece, mas o interesse dirigido ao computador passa a ser de outro tipo: busca-se apreender como ele aparece, ou seja, quais leis estruturais regulam o seu aparecimento. Neste nível, a problemática do outro não está explicitamente presente, ou, se está, encontra-se afetada de certa ingenuidade. O "outro" fez o computador, inventou a linguagem de programação, fabricou, comercializou etc. Ele não aparece como um Eu capaz de efetuar a redução fenomenológica, mas sim como alguém cuja existência aparece envolta num certo anonimato; alguém com quem eu posso contar, que partilha o meu mundo, mas com quem apenas me relaciono de forma indireta. (Por exemplo, uma relação comercial, no caso de ele ser o vendedor do computador e eu o seu eventual comprador.)

O objeto "reduzido" — o computador — remete permanentemente para a presença do outro, porém esse outro não é tematizado por mim de forma explícita, não se interroga sobre ele, numa atitude de ingenuidade que Husserl visa ultrapassar. O fenômeno on-line está implicado na cultura e as transformações proporcionadas à humanidade vêm se caracterizando por um 


\section{ARTIGOS}

continuum, sem limites. É no mundo da vida, histórico e cultural, onde ele aparece: as novas formas de comunicação e informação decorrentes do desenvolvimento acelerado das tecnologias digitais, promovem implicações nos modos de relacionamento, com o alargamento das formas de interação, o que suscita reflexões sobre o ser humano, que é quem gera tais aparecimentos e quem vivencia o universo on-line, mas, também, sobre como essa mediação se desvela no mundo da vida, nas relatividades da subjetividade e da intersubjetividade do humano (Sokolowski, 2012). Ainda, o fenômeno que ocorre na internet não remete apenas à tecnologia ou às mudanças psicológicas interconectadas ao digital, mas se trata de considerar profundamente as relações entre as subjetividades que se pousam nesta realidade, que, por sua vez, se constitui em novas estruturas, ainda que não palpáveis, e que doam e constituem sentidos através da interação entre experiências de novas percepções humanas, linguagens computacionais decodificadas e de transformações espaço-temporais. Trata-se, portanto, da relação entre o mundo e o homem, o conhecimento e a consciência, um fenômeno complexo que abrange uma amplitude de perspectivas.

É da constituição humana não apenas a possibilidade de captar o sentido do que se desvela no mundo, mas também de criar outras formas de manifestação. Sokolowski (2012) trata de modo introdutório a respeito da compreensão pós-moderna de aparência, presente desde a origem da filosofia, mas que recentemente tem aumentado e vem se multiplicando, colocando, em especial, a expansão tecnológica das palavras e das imagens como um risco, onde tudo pode se reduzir a meras aparências. Segundo o autor:

Nós os geramos [os aparecimentos] não só por palavras faladas ou escritas de uma pessoa a outra, mas por microfones, telefones, filmes e televisão, bem como computadores e pela internet, pela propaganda e pela publicidade. Os modos de apresentação e representação proliferam e questões fascinam e afloram: como diferenciar uma mensagem de e-mail de uma chamada de telefone e de uma carta? Quem se dirige a nós quando lemos uma página na $w e b$ ? De que modo são modificados os falantes, os ouvintes e a conversação pela maneira como nos comunicamos agora? (p. 10)

O on-line é evidenciado em aparecimentos que ocorrem através de uma multiplicidade de perspectivas e compartilhamentos no formato de janelas (Windows) que não circunscrevem uma linearidade de conhecimento. $\mathrm{O}$ acontecer temporal do on-line passa a se configurar a partir de uma alternância de perspectivas, assumindo encadeamentos de atos valorativos, normativos e relacionais que se dissolvem em janelas síncronas ausentes da 
espacialidade concreta. As percepções de tempo e espaço se separam, numa temporalidade imediata e espacialidade multidimensional, sem corpo físico. Os paradigmas e valores dominantes até então, contrastam-se com experiências de fragmentação e multiplicação da identidade e da vida, modificando, também, as percepções do tempo histórico, que passa a ser vivenciada cada vez mais de modo fugaz.

As compreensões do universo on-line por meio de correlações antes não captadas, referem-se ao problema das aparências no mundo pós-moderno (Sokolowski, 2012). O universo digital gera alterações nos modos de aparecimento, quebrou as lógicas habituais de sucessão temporal e de contiguidade espacial. Parece, às vezes, que essas duas noções — sucessão e contiguidade - perderam o seu sentido, tal a novidade que o universo digital introduziu na vida e no sentido de realidade.

Anterior à generalização do uso das tecnologias digitais, as partes eram apenas compreendidas em contraste com apropriação do todo, as multiplicidades das aparências remetiam a identidades; já as ausências contrastavam com as presenças, sendo as ausências somente atingidas através da presença. Nessa perspectiva, o on-line parece se desvelar de modo a proliferar fragmentos ausentes de totalidade, a expressar multiplicidades sem identidades, além de presenças ausentes e não duradouras, em que se torna possível ao ser humano inventar a si próprio ao acaso por meio de peças convenientes e agradáveis, ainda que passageiras, identidades a partir de bits e partes encontradas sobre cada um e cada ser humano.

Assiste-se a uma amplificação dos acessos à informação, um informar-se individualizado a partir de um fluxo coletivo simultâneo e imediato - o on-line — intermediado pela matéria física — os dispositivos — que assume uma pluralidade ilimitada de sentidos e possibilidades. O avanço tecnológico tem, também, promovido um esmaecimento da dicotomia entre o científico e o cultural, com uma transformação radical na relação entre o homem e o mundo e na esfera dos valores, que afetam e modificam o mundo da vida.

As vivências humanas hibridas-tecnológicas plasmam o mundo circundante e este se apreende nas experiências subjetivas e intersubjetivas. $\mathrm{O}$ fenômeno on-line, da mesma forma, plasma o mundo e as vivências que ocorrem na interface do digital com o humano, promovendo uma reconfiguração perceptiva na dimensão da consciência. Os bits e os inputs computacionais modificam as experiências sensoriais, e, também, atingem o mundo da vida e a cultura, transmitidas através de novas formas de comunicação. A ausência do corpo físico somado à dinamicidade, a fragmentação, a não 
linearidade do conhecimento, a alternância de perspectivas e a infinidade de possibilidades de informação que rompem com regiões culturais individualizadas, geram no mundo da vida experiências interculturais ilimitadas, sem os confins físico-geográficos, alterando, por sua vez, o modo como se qualifica e se valoriza os relacionamentos.

A navegação on-line e as, ainda, incipientes mudanças no mundo da vida, são apreendidas não apenas na dimensão da materialidade, enquanto corpo físico, mas também na aproximação com o mundo natural-perceptivo da subjetividade, diretamente implicada na consolidação das novas tecnologias. Portanto, definir as mídias digitais enquanto um objeto físico, como instrumentos derivados, criados e dirigidos para o humano, úteis em sua materialidade física, distancia a necessária discussão sobre a relevância de uma consciência implicada nos valores de uso e do alavancamento evolutivo das potencialidades humanas, em que os ambientes digitais individualizam novas qualidades culturais.

O tema do corpo e da corporeidade é, também, relevante na evidenciação das vivências on-line. Anterior aos seus estudos sobre a intersubjetividade, em Ideias II, Husserl trata a respeito da constituição da natureza material e sintetiza que "os corpos sólidos se constituem como provenientes de uma forma espacial rígida, que se mantém ainda que em movimento" (Husserl, 1952, p. 56; tradução nossa) e que estão condicionados aos fatores subjetivos e intersubjetivos da constituição. Subsidiando as novas tecnologias, a relação homem-natureza se inicia na transformação dos elementos de natureza material, como silício, ferro, evoluindo para ondas elétricas até as criações digitais, que resultam em novas tecnologias que passam a ser inseridas no corpo através da biotecnologia e novos dispositivos, como as tecnologias vestíveis (wearable), monitorando as vivências e modificando a corporeidade.

Embora no senso comum diga-se que o corpo não está presente nas interfaces da $w e b$, a fenomenologia promove uma reflexão acurada. O corpo-soma ou corporeidade vivente (Leib), com sua experiência sensível, está plenamente presente no on-line, seja como um corpo-soma representado ou corposoma afetado. O virtual - on-line — afeta intensamente as percepções vitais, audição, visão, tato, ultrapassando e modificando as experiências concretas de espacialidade e temporalidade. As máquinas servem como um suporte para uma materialidade física, com sua específica capacidade de atualizar artificialmente as dimensões do espírito, alterando e ressignificando, também, as expressividades da psique. Porém, o on-line modifica as experiências do 
toque e do tato, ao mediar encontros em que o corpo soma é representado em imagem, sem a percepção da resistência da matéria, a prova definitiva da realidade, que não acontece simultânea à percepção do corpo alheio, em sua solidez material. O que o on-line promove é, portanto, a des-subordinação da resistência do corpo físico à corporeidade viva, promovendo experiências que transcendem os limites do tempo ou do espaço. A ausência do corpo físico promove o caráter fugaz, instantâneo, não linear, múltiplo, confirmando as características de fluidez, temporalidade e espacialidade modificadas da vivência on-line.

As novas tecnologias tornam-se capazes de captar as diferentes experiências e as individualizam em aspectos comuns, oferecendo a possibilidade de atualizações simultâneas das potencialidades subjetivas. Como exemplificação, Sorj, Cruz, Santos, Ribeiro e Ortellado (2017) comentam sobre o efeito bolha da internet, em que os dados inseridos nos aplicativos alimentam um banco de informações que, através de uma coleta detalhada, é feito um mapeamento da própria personalidade a partir das "pegadas digitais", sendo capazes de definir gostos, preferências, visão de mundo e crenças. Segundo Sorj et al. (2017), essas informações são usadas para direcionamento publicitário, mas reflete, também, no espelhamento e reprodução de ecos de si mesmo. $\mathrm{O}$ indivíduo se torna o centro das próprias experiências no on-line, seja em relação a si mesmo ou ao encontro, na medida em que se pode cancelar, deletar ou bloquear pessoas e temáticas que desagradam ou não são afins, com uma sintonia de valores muitas vezes provocadas por algoritmos programados para buscar a satisfação do usuário.

Sem a materialidade, a vivência on-line intersubjetiva efetua-se na ausência do corpo físico, de sua impressão digital, sua identidade, e da percepção do outro; ela promove um fluxo de experiências sem a resistência, o atrito e os limites que a materialidade coloca à relação efetiva. Embora seja possível imaginar e se colocar analogamente em relação ao outro, a vivência corpórea digital não apreende simultaneamente as percepções sensíveis imediatas do tempo e do espaço do outro. A temporalidade objetiva e as apreensões da matéria deixam de afetar a subjetividade. Intensificam-se os atos internos, em detrimento do atrito concreto com as experiências da espacialidade do outro, que transcendem a dimensão física do Eu.

A tecnologia em seus diversos usos, seduz o humano, subjetivamente, ao identificar e promover o aprimoramento singular, a atualização artificializada de características e capacidades, desejos e escolhas (Silva, 2020). A "pegada digital" parece alterar a constituição da identidade pessoal, por meio 
de um número de experiências e intercâmbios que em sua maioria escapam à consciência. A internet passa a ser a detentora de todas as experiências on-line (interações, compras, viagens, preferências), com uma capacidade de armazenamento superior às lembranças e memórias humanas, condicionando as escolhas futuras que deixam de acontecer através de relações humanas e passam a ser determinadas por interações digitais.

\section{Da subjetividade à intersubjetividade on-line}

Embora desenvolvido para comunicar e compartilhar dados, o fenômeno da Revolução Tecnológica que resultará no on-line, passa gradativamente a ser incrementado com características da consciência humana, tornando-se matérias físicas constituídas "a partir de" e "para as" subjetividades. Tais ferramentas não apenas são aparatos físicos, mas também recebem inputs para escolha (buscadores on-line), decisão (algoritmos), autonomia (inteligência artificial), informação e conhecimento imersivos (realidade virtual, realidade aumentada, gamificação). Na interface dessa relação, cria-se, portanto, uma materialidade híbrida com aspectos da subjetividade humana: computadores, robôs e máquinas capazes de assimilar conhecimento, de transformar dados analógicos em codificações compreensíveis aos aparatos digitais e que re-traduzem tais códigos para a compreensão humana e podem gerar novas formas de percepção da vida, como, por exemplo, a realidade virtual ou programas de imersão on-line e a biotecnologia. A matéria passa a ser constituída por essencialidades da subjetividade humana, decisão, escolha, autonomia, que, gradativamente, são inseridas nas novas tecnologias. Porém, não são humanas e diferem exatamente porque a subjetividade é corporal, possui características específicas que marcam a singularidade do humano, razão pela qual é chamada de matéria orgânica.

Outro aspecto que diferencia as criações do mundo da vida, como por exemplo, livro, caderno ou mesmo formas de comunicação eletrônicas mais tradicionais, como televisão e rádio, é que em qualquer perspectiva da interação on-line, a experiência do outro está implicada direta, simultanea e ativamente. Isso significa que o fenômeno on-line não existe por si próprio sem necessariamente legitimar uma multiplicidade de subjetividades envolvidas agindo e interagindo ao mesmo tempo, num movimento constante de inserções e ações humanas. Evidencia-se, portanto, entre as essencialidades do on-line a sua configuração enquanto intersubjetividade de tipo particular. A 
internet e suas qualificações existem no mundo da vida e se configuram se, e somente se, forem vivenciadas intersubjetivamente.

$\mathrm{O}$ fenômeno on-line não existe, portanto, senão em sua condição de conexão de intersubjetividades, que deixa de ser um meio e passa a ser um universo dinâmico de construção e desconstrução imediata de identidades, como um campo próprio que promove mudanças também na esfera da sociedade. Apreendem-se, portanto, experiências do espírito desconectadas das características físicas do corpo material, evidenciando o modo como as tecnologias digitais seduzem o humano, influenciam as subjetividades à expressão e atualização das potências enquanto constituição de um fluxo híbrido de vivências.

No cerne do processo de digitalização da vida, inserções de escolha, decisão e autonomia também constituem os dispositivos digitais, seja mediado por uma subjetividade primeira (pessoas que desenvolvem, valoram e criam), seja por meio de seus usuários que recebem as informações e comunicações on-line, mas também por meio de uma própria possibilidade das novas tecnologias de buscar, expressar conhecimento e influenciar. Esses elementos tecnológicos oferecem a possibilidade de potencializar o aprimoramento das próprias capacidades subjetivas. Entretanto, estabelece-se um novo ciclo de conhecimento, pois na outra ponta do dispositivo digital, por meio da interface objetiva, há milhares de outras subjetividades interagindo on-line ao mesmo tempo, e esses sujeitos passam a promover, também ativa e simultaneamente, mudanças nessa totalidade.

Trata-se de uma ferramenta de múltipla interação, em que há a atualização do campo subjetivo singular por meio dos acessos da web e, por outro lado, as tecnologias passam a ser incrementadas por atos constituintes do humano, como exemplo os usos de inteligência artificial (escolha, decisão). Num processo de troca contínua, há a interação e modificação do fluxo de ocorrências do on-line e, por outro lado, também do fluxo de consciência humana.

Tem-se, portanto: (1) a possibilidade humana de intervir na matéria, tornando-a detentora de características subjetivas, mas também, (2) a possibilidade de múltiplos humanos simultâneos atualizarem suas subjetividades nessa materialidade, alimentando-a, e tornando-a cada vez mais enriquecida e com maior acesso às potencialidades humanas, acesso esse que só acontece intersubjetivamente.

Dessa forma, existe um caminho múltiplo de duplicação de subjetividades inseridas no on-line. Os dispositivos podem ser mediados por algoritmos, que podem ser determinados por certos valores humanos, como por 


\section{ARTIGOS}

exemplo o uso da publicidade e da manipulação digital que vem ocorrendo atualmente. Mas também a capacidade desses dispositivos reproduzirem a cognição humana, adquirindo, através dessas perspectivas poliédricas de informação e conhecimento, um fluxo de consciência próprio, alimentado obrigatoriamente pelas subjetividades nela inserida. Grande parte do conhecimento humano hoje está inserido no digital, através e para o compartilhamento, seja de informação, de literaturas, de imagens, de selfies ou documentos, todas as formas possíveis de produção espiritual humana. Portanto, um outro aspecto do fenômeno on-line é a criação de um fluxo de vivências que se correspondem e complementam "por meio da" e "na" matéria. $\mathrm{O}$ on-line, é, portanto, um fluxo construído de experiências subjetivas que interagem e se interconectam simultaneamente e, ainda, fluxo esse capaz de gerar processos materializados de decisão, autonomia e escolha.

Portanto, além das caraterística de (1) subjetivação da matéria pelo humano, (2) da interação simultânea de subjetividades na interface da materialidade, modificando-a e dotando-a de um fluxo próprio de vivências traduzidas ao campo digital, um terceiro aspecto se depreende, (3) que é a explicitação de uma comunidade de conhecimento. Através das redes de computador, rompe-se uma linha hierárquica do conhecer e este passa a ser, horizontalmente, de todos que nela interagem. Isso provoca uma ruptura de padrões antes determinados, uma ilimitada possibilidade de "verdades", e um compartilhamento simultâneo do mundo da criação e da cultura, do mundo da vida.

Em estudo fenomenológico sobre as selfies, Trilles-Calvo (2019) aponta que as transformações também ocorrem na espacialidade, o homem passou a ocupar distintos espaços ao mesmo tempo (multidimensionalidade) e a modificá-los, o que implica o poder de duvidar da veracidade deles, que se apresentam no ciberespaço principalmente por meio de imagens plurais e abertas, e, consequentemente, em uma temporalidade que ora se encurta e ora se alonga. A revolução numérica promovida pelas tecnologias estão presentes nas experiências com humanos ou com objetos, e isso tem modificado substancialmente o modo como as novas gerações participam do mundo, não no sentido de serem insensíveis ou atribuírem menos importância ao redor, ou de estarem mais ou menos impacientes, mas, simplesmente, com uma maneira diversa de se relacionarem com a alteridade.

Chega-se, portanto, ao problema central deste estudo, que é compreender a intersubjetividade on-line, que implica, também, a alteridade on-line. Segundo Manganaro (2007), a corporeidade vivente possibilita a compreensão das relações intersubjetivas, o corpo-soma permite apreender a 
psique e o espírito, esse corpo revela a peculiaridade humana, a sua unicidade, dignidade, inviolabilidade e liberdade, sendo o Leib o único dado objetivável da alteridade pessoal.

A legitimidade da subjetividade própria e da subjetividade do outro na esfera on-line, passa por uma dupla possibilidade de compreensão: nas relações intersubjetivas on-line, a apresentação do outro enquanto corpo somático acontece pelo dispositivo físico digital, sem a possibilidade de trocar o "aqui" em que se encontra (ou seja, diante do computador) pelo "ali" onde vê o outro, justamente porque o vê apenas em imagem. Essa dimensão da relação intersubjetiva, que Husserl, nas Meditações cartesianas (Husserl, 1950a), considerava essencial não se pode levar a cabo em contexto digital. Mas, por outro lado, há um espelhamento de si mesmo psíquico-espiritual nas telas, quando cada um livremente se expressa e se comunica, busca suas realizações e acessa o mundo da cultura, se representa de formas individualizadas, sem necessariamente ter o reconhecimento e o confronto com a outra subjetividade implicada. O que não está presente é o limite físico do corpo alheio, e em consequência a sensibilidade do toque e do contato concreto e, portanto, o lado objetivo da alteridade.

As até então conhecidas interações homem-matéria, como acessar os bens culturais, ler um livro ou ver um filme, aconteciam dentro dos limites do corpo. Buongiorno (2019) estuda a mente digital ampliada, e refere que há duas características essenciais: a primeira é a da desmaterialização, que significa uma desencarnação de símbolos e dos sujeitos no contexto on-line, como acontece nas teleconferências, com a ausência do corpo no contato face a face. Conectado a esta, ocorre uma segunda mudança, que é a re-remodelação ou re-codificação, em que a liberdade de reconfigurar-se, como por exemplo através de avatar, como uma representação do eu ideal, podendo assumir a forma que se deseja, o que confirma que a interação homem-máquina ativamente modifica o modo de estar no mundo e de se relacionar com outras pessoas, ao promover novas experiências e significações para o mundo da vida. Trata-se de experimentar as potencialidades e os limites da própria identidade, segundo modalidades que na vida concreta dificilmente acontecem.

\section{Considerações finais}

As tecnologias, quando utilizadas como meios ou simples ferramentas de trabalho, trazem o risco da recusa e do desconhecimento das implicações 
do on-line nas várias regiões do mundo da vida. Tais reflexões são válidas ao se considerar atividades, ações e intervenções via internet, especialmente nas áreas que se debruçam aos estudos da subjetividade. A compreensão fenomenológica sobre as vivências híbridas humana-digital contribui para a não naturalização da psique e para a legitimação de seus novos aparecimentos, enquanto um centro de ações reais e potenciais o que, por sua vez, ressoa no campo do cuidado à saúde mental. $\mathrm{O}$ fenômeno on-line que ocorre no mundo da vida afeta a compreensão de si mesmo e da relação com o outro, na medida em que interfere, de modo particular, nas dimensões culturais e na possibilidade de novas percepções individuais sobre o mundo.

No mundo da vida, as janelas virtuais, em seu caráter infinito e dinâmico, ampliam o acesso à informação e atingem de modo equânime a todos que nelas habitam. Isso promove um esmaecimento da hierarquia entre o científico e cultural, modifica a esfera de valores no mundo da vida e rompe com paradigmas e valores preestabelecidos. Modifica as percepções de geolocalização, bem como as vivências intersubjetivas de espacialidade, temporalidade e corporeidade. As ofertas ilimitadas de vivências on-line ampliam, também, os modos de apreensões sobre os sentidos da vida, modificando, por sua vez, as atitudes requisitadas àqueles que se dedicam ao cuidado psicológico.

Os valores, as normas e os modos de relacionamento, antes determinados por regiões físicas geográficas, passam a ser acessíveis independentemente da matéria e do espaço. A fragmentação das perspectivas, a dinamicidade e velocidade de transmissão da informação sem a materialidade e espacialidade concreta da experiência, promovem no mundo da vida experiências interculturais ilimitadas. Rompe-se com os confins físico-geográficos, alterando, também, o modo como se qualifica e se valora os relacionamentos.

$\mathrm{O}$ fenômeno on-line não ocorre por si próprio e implica o envolvimento de uma multiplicidade infinita de subjetividades que agem e interagem, com movimentos constantes de inserções e ações humanas. O on-line possui, portanto, entre suas essencialidades, a configuração enquanto intersubjetividade, sua estrutura acontece no mundo da vida e se configura se, e somente se, forem vivências intersubjetivas simultâneas.

A intensificação da vida on-line na subjetividade, por sua vez, promove o desenvolvimento de esferas únicas, atrai e seduz o homem e o desejo da infinita e perpétua evolução. O esvaziamento do sentido da subjetividade na ciência expande-se para as diversas esferas da vida digital, num movimento paradoxal de reconhecimento de si mesmo, porém, através do espelhamento não mais somente de outro humano, mas também das telas on-line. Tornam-se 
possíveis diversas e infinitas representações do eu ideal inseridas nas janelas virtuais, com repercussões significativas nos sentidos de identidade, enquanto esfera única, que passa a ser passível de apreensão através de identidades multifacetadas que, antes da ascensão da vida híbrida, não eram possíveis de serem experienciadas. $\mathrm{O}$ fenômeno on-line promove subjetivamente vivências simultâneas infinitas, síncronas, múltiplas, poliédricas e bidimensionais, com janelas virtuais (windows) que repercutem numa reconfiguração perceptiva da consciência. $\mathrm{O}$ conhecimento deixa de acontecer de modo linear e se amplia através de uma alternância de perspectivas que rompem com lógicas habituais de sucessão temporal e contiguidade, e tornam a experiência do tempo histórico fugaz. Isso repercute em mudanças na percepção da história; o tempo e o espaço são reconfigurados, na medida em que a vivência é sempre imediata e a espacialidade multidimensional ocorre sem a matéria física. Considerar essas alternâncias no rol do saber psicológico exige o reposicionamento e rompimento de fundamentos antes legitimados, em vistas de abranger as necessárias discussões das esferas da psique que emergem do mundo on-line.

A intersubjetividade cada vez mais objetivada aparece nas relações face a face e as interações digitais confirmam uma dissociação do Körper-Leib, com 632 uma intensificação do corpo enquanto objeto e uma exacerbação do corpo vivente sem corpo físico na vida on-line.

O risco do não reconhecimento do corpo físico alheio semelhante ao corpo próprio e o distanciamento do tempo e do espaço comum podem distorcer as noções compartilhadas de limite, de ritmo e andamento, de concretude da vida, repercutindo em vivências de empatia e de alteridade, desenraizadas da resistência e atrito do corpo físico. Vale indagar sobre as repercussões da ausência de limites, de concretude, das percepções sensíveis e cinestésicas advindas da experiência intersubjetiva on-line. Tais aspectos inseridos nos cuidados em saúde mental digital, nas diversas esferas do sofrimento psíquico, considerando suas alterações no afetar-se e ser afetado subjetivamente, ampliam a necessidade de abarcar estudos voltados aos aspectos próprios da intersecção entre subjetividade e on-line.

Os aspectos essenciais da estrutura humana, como a capacidade de decisão, de escolha e autonomia, são inseridos em produtos tecnológicos, mas diferem do humano porque a subjetividade também se faz através da corporeidade, característica da singularidade humana, em unidade psíquica, espiritual e orgânica. O orgânico e a ressonância interpessoal corpórea são aspectos ainda não transpostos para as tecnologias e que aparentam estar em risco ao se vislumbrar uma vida imersa no on-line. Os relacionamentos pessoais, que 


\section{ARTIGOS}

antes eram vivenciados a partir de outro humano ou da natureza física, passam a acontecer também por meio de novos dispositivos que alteram as noções de empatia e alteridade em seus aspectos de organicidade do corpo o que, por sua vez, influencia na consolidação da identidade pessoal. Tais problematizações realçam a importância de considerar novas perspectivas, ao se tratar da mediação das tecnologias nas relações de cuidado psicológico, ao promover questões sobre vínculo terapêutico, afeto, empatia e cuidados clínicos on-line.

Conclui-se que o fenômeno on-line afeta a subjetividade e a intersubjetividade, sendo relevante uma postura crítica diante das vivências híbridas humanas. Nessa linha, sugere-se o incentivo à literacia digital, no sentido de promover o conhecimento e a dupla alfabetização das diversas gerações. Trata-se da possibilidade de formar, informar e compreender o que são e quais os sentidos e usos possíveis da tecnologia, seja para a vida concreta, como mediadores do cuidado psicológico ou de suas repercussões na subjetividade. Ao mesmo tempo, destaca-se a importância de legitimar as cinestesias de Körper/Leib, reafirmando e incentivando as experiências concretas e sensíveis no mundo.

Agradecimentos: A Andrés Eduardo Aguirre Antúnez, professor associado do Departamento de Psicologia Clínica do IPUSP, coordenador do Escritório de Saúde Mental ESM-USP, supervisor do projeto de pós-doutorado.

\section{Referências}

Álvarez, J. D. (2003). Husserl y la historia. Hacia la función práctica de la fenomenología. Madrid, ES: UNED.

Buongiorno, F. (2019). From the extended mind to the digitally extended self: A phenomenological critique. Aisthesis 12(1), 61-68.

Husserl, E. (1950a). Cartesianische meditationen. Den Haag: Martinus Nijhoff.

Husser1, E. (1950b). Ideen zu einer reinen phänomenologie und einer phänomenologischen philosophie, Erstes Buch. Husserliana III. Den Haag, HOL: Martinus Nijhoff.

Husserl, E. (1952). Ideen zu einer reinen phänomenologie und einer phänomenologischen philosophie, Zweiter Buch. Husserliana IV. Den Haag, HOL: Martinus Nijhoff. 
Husserl, E. (1954). Die Krisis der europäischen wissenchften und die transzendentale phänomenologie. Husserliana VI. Den Haag, HOL: Martinus Nijhoff.

Husserl, E. (2012). A crise das ciências européias e a fenomenologia transcendental. Uma introdução à filosofia fenomenológica. Rio de Janeiro, RJ: Forense Universitária.

Husserl, E. (1987). Philosophie als strenge Wissenschft, in Vorträge und Aufsätze (1911-1921), Husserliana XXV, Dordrecht / Boston / Lancaster, Martinus Nijhoff, p. 13-62.

Husserl, E (1988). Conferenze di Amsterdam: psicologia fenomenológica e fenomenologia trascendentale, trd. It. A cura di P. Polizzi, Ila-Palma, Palermo, p. 110-117. (Trabalho original publicado em 1928).

Manganaro, P. (2007). "Einfühlung” e "mind-body problem". Dalla svolta linguística alla svolta cognitiva. Aquinas, 2(1), 465-494.

Sanchez, D. G. (2014). Fenomenologia e subjetividade: Propedêutica à teoria da intersubjetividade a partir de meditações cartesianas. Trilhas Filosóficas, 7(1), 11-23.

Silva, N. H. L. P (2020). Virtualidade, violência on-line e corpo: uma compreensão fenomenológica. Internet\&Sociedade. 1(1), 311-330. Recuperado de: $<$ https://revista.internetlab.org.br/wp-content/uploads/2020/02/Virtualidadeviole $\%$ CC $\% 82$ ncia-on-line-e-corpo.pdf $>$.

Solari, S. (2005). Nuove tecnologie e simbolizzazioni dela corporeità. Laurea Liv. II, Università Cattolica del Sacro Cuore di Milano, Facultà di Lettere e Filosofia, Corso teoria e tecniche della comunicazione mediale. Milão, Itália. Recuperado de: <https://www.tesion-line.it/tesi/14105/nuove-tecnologie-e-simbolizzazionidella-corporeit $\% \mathrm{C} 3 \% \mathrm{~A} 0>$.

Sokolowski, R. (2012). Introdução à fenomenologia. (3ª ed.). São Paulo, SP: Loyola.

Sorj, B., Cruz, F., Santos, M., Ribeiro, M., \& Ortellado, P. (2017). Sobrevivendo nas redes - guia do cidadão, 3. Coleção: Ensaios Democracia Digital. Recuperado de: <http://www.internetlab.org.br/wpcontent/uploads/2018/05/Sobrevivendo nas_redes.pdf $>$.

Trilles-Calvo, K. P. (2019). La imagen (re)doblada de lo que puede ser un selfie. Una aproximación fenomenológica. In M. C. L. Saenz, \& K. P. Trilles-Calvo (Orgs.), A las imágenes mismas - fenomenología y nuevos medios (pp. 255-266). Madrid, ES: Apeiron Ediciones.

Zilli, M. (2008). Tecnología, comunicazione e uomo. Laurea Liv. I, Università degli Studi di Teramo, Sicenze Politiche, Corso economía, statistica e informatica per l'azienda, Teramo, Itália. Recuperado de: <https://www.tesion-line.it/tesi/ tecnologia-comunicazione-e-uomo/22873\#>. 


\section{ARTIGOS}

\section{Resumos}

(A phenomenological reading on intersubjectivity in the digital /on-line world)

This article reflects on on-line experiences and the relationship with the world of life, subjectivity and intersubjectivity. Husserl's works (1950a, 1950b, 1952, 1954) were used to return to the experienced intuition that is methodologically guided by phenomenological reductions. Understanding the structuring aspects through reductions allows to highlight the implications of hybrid life, such as fragmentation of perspectives, dynamicity and speed of information transmission through two-dimensional images in windows format that lack actual materiality and spatiality, but which promote a perceptual reconfiguration of consciousness. In the world of life, the hierarchy between science and culture has been vanishing, which changes the sphere of values, breaks with the usual logics of temporal succession and contiguity and makes the experience of historical time elusive. This article also reflects on the insertion of technologies in mental health care; it suggests encouraging digital literacy and legitimizing sensitive experiences in the world.

Key words: Phenomenology, phenomenological psychology, Internet

(Une lecture phénoménologique de l'intersubjectivité dans le digital/en ligne)

Dans cet article, on cherche à réfléchir sur les expériences en ligne et la relation avec le monde de la vie, la subjectivité et l'intersubjectivité. Les travaux de Husserl (1950a, 1950b, 1952, 1954) ont été utilisés visant à revenir à l'intuition vécue et guidée méthodologiquement par des réductions phénoménologiques. Comprendre les aspects structurants à travers les réductions permet de mettre en évidence les implications de la vie hybride, telles que la fragmentation des perspectives, la dynamicité et la vitesse de transmission de l'information à travers des images bidimensionnelles en format de fenêtres dépourvues de matérialité et spatialité concrète qui favorisent une reconfiguration perceptuelle de la conscience. Dans le monde de la vie, on observe un effacement de la hiérarchie entre le scientifique et le culturel qui change la sphère des valeurs, rompt avec les logiques habituelles de succession temporelle et de contiguïté et rend insaisissable l'expérience du temps historique. On réfléchit sur l'insertion des technologies dans les soins de santé mentale, suggère d'encourager l'alphabétisation numérique et de légitimer les expériences sensibles dans le monde.

Mots-cles: Phénoménologie, psychologie de la phénoménologie, Internet

(Una lectura fenomenológica sobre la intersubjetividad en lo digital/en línea)

Este trabajo busca reflexionar sobre las experiencias en línea y la relación con el mundo de la vida, la subjetividad y la intersubjetividad. Se utilizaron las obras de Husserl (1950a, 1950b, 1952, 1954), pretendiendo retornar a la intuición 
experimentada y orientada metodológicamente por reducciones fenomenológicas. Comprender los aspectos estructurales a través de las reducciones permite resaltar las implicaciones de la vida híbrida, como la fragmentación de las perspectivas, la dinámica y la velocidad de transmisión de la información por medio de imágenes bidimensionales en formato de ventanas, sin materialidad y espacialidad concreta, que promueven una reconfiguración perceptiva de la conciencia. En el mundo de la vida, hay un deterioro de la jerarquía entre lo científico y lo cultural, que modifica la esfera de valores, rompe con las lógicas habituales de sucesión temporal y contigüidad, y hace que la experiencia del tiempo histórico resulte efímera. Se reflexiona sobre la incorporación de tecnologías en el cuidado de la salud mental. Se sugiere fomentar la alfabetización digital y legitimar experiencias sensibles en el mundo.

Palabras clave: Fenomenología, psicología fenomenológica, internet

Citação/Citation: Silva, N. H. L. P. da, \& Morujão, C. A. V. (2021, dezembro). Uma leitura fenomenológica sobre a intersubjetividade no digital/on-line. Revista Latinoamericana de Psicopatologia Fundamental, 24(4), 614-637. http://dx.doi.org/10.1590/1415-4714.2021v$24 \mathrm{n} 4 \mathrm{p} ? 614.7$

Editora/Editor: Profa. Dra. Ana Maria R. G. Oda

Submetido/Submitted: 21.11.2020 / 11.21.2020 Revisado/Revised: 13.4 .2021 / 4.13.2021

Aceito/Acepted: $23.4 .2021 / 4.23 .2021$

Copyright: (C) 2009 Associação Universitária de Pesquisa em Psicopatologia Fundamental/ University Association for Research in Fundamental Psychopathology. Este é um artigo de livre acesso, que permite uso irrestrito, distribuição e reprodução em qualquer meio, desde que o autor e a fonte sejam citados / This is an open-access article, which permits unrestricted use, distribution, and reproduction in any medium, provided the original authors and sources are credited. 


\section{ARTIGOS}

Financiamento/Funding: Este trabalho recebeu apoio da Fundação de Apoio a Pesquisa do Estado de São Paulo - Fapesp (processo 2018/11351-2) (São Paulo, SP, Br) / This work is supported by Fundação de Apoio a Pesquisa do Estado de São Paulo - Fapesp (processo 2018/11351-2) (São Paulo, SP, Br).

Conflito de interesses/Conflict of interest: Os autores declaram que não há conflito de interesses. / The authors declare that there is no conflict of interest.

Nara Helena Lopes Pereira da Silva

Instituto de Psicologia, Departamento de Psicologia Clínica, Universidade de São Paulo

- USP (São Paulo, SP, Br).

Rua Afonso Celso, 1221/53

04119-061 São Paulo, SP, Br.

nara.helena@gmail.com

https://orcid.org/0000-0001-6183-3709

Carlos Aurélio Ventura Morujão

Faculdade de Ciências Humanas, Universidade Católica Portuguesa (Lisboa, Portugal).

cmorujao@fch.lisboa.ucp.pt

https://orcid.org/0000-0001-9943-8229

This is an open-access article, which permits unrestricted use, distribution, and reproduction in any medium for non-commercial purposes provided the original authors and sources are credited. 